\title{
Some Candles Emit Hazardous Materials for Human Health and are Indoor Air Pollutants
}

\author{
Ruhullah Massoudi ${ }^{1^{*}, \#}$ and Amid Hamidi ${ }^{1 \dagger}$ \\ ${ }^{1}$ Department of Biological and Physical Sciences, South Carolina State University,
} USA.

Authors' contributions

This work was carried out in collaboration between both authors. Author RM designed the study, performed the statistical analysis, wrote the protocol and wrote the first draft of the manuscript. Author AH managed the analyses of the study and literature searches. Both authors read and approved the final manuscript.

Article Information

DOI: $10.9734 /$ IJTDH/2017/34965

Editor(s):

(1) Jorge Paredes Vieyra, Universidad Autonoma De Baja California, Campus Tijuana, Mexico.

Reviewers:

(1) Hideharu Shintani, Chuo University, Japan. (2) João Fernando Pereira Gomes, ISEL - Lisbon Polytechnic, Portugal. Complete Peer review History: http://www.sciencedomain.org/review-history/20001

Original Research Article

Received $21^{\text {st }}$ June 2017

Accepted $5^{\text {th }}$ July 2017

Published 11 ${ }^{\text {th }}$ July 2017

\section{ABSTRACT}

Aims: The purpose of this study is to evaluate the effect of burning candles from paraffin sources to determine whether indoor environment under that condition is safe and healthy for human.

Study Design: Burning chamber ( 8 " $\times 8$ " $\times 26$ ") attached to a vacuum pump on the top, was constructed locally, and Coconut Charcoal CSC Cat. No. 226-01GWS was purchased from SKC, Inc. The adsorbed emission products on the charcoal were extracted by a given volume of carbondisulfide, and after filtration injected into a GC/MS equipped with NIST library of compound allowing us to identify all the components.

Place and Duration of Study: All the study was carried out at South Carolina State University from January 2008 till June 2010.

Methodology: A candle burning chamber was constructed, while candles were burning under normal condition, the emission products were adsorbed on coconut charcoal and extracted with carbon disulfide. The extracted samples were injected into a GC/MS system under the temperature 
and flow rate conditions to produce chromatograms and also to identify those substances present in the samples. The ill-health effects of all emission products are available in literature.

Results: Several kinds of paraffin candles were examined, the samples produced various hazardous products including benzene, toluene, and alkenes.

Conclusion: Paraffin candles are hazardous for human health to be burned in enclosed and limited areas.

Keywords: Paraffin candle; human health; asthma; cancer; dermatitis; indoor pollution.

\section{INTRODUCTION}

Currently, there are many different types of candles manufactured in the United States. These include tapers, straight-sided dinner candles, spirals, column, votives, tealights, waxfilled containers, and novelties. Most candles on the market today are petroleum-based and are composed of derivatives or by-products of fossil fuels. The main ingredient used in their manufacture is paraffin wax; it tends to give the candle more stability and firmness. In addition, some candle manufacturers utilize vegetable wax, animal wax, or insect wax [1]. However, it is the widespread use of paraffin candles which produce unwanted emissions and causes indoor pollution and health concerns.

The potential indoor air impacts of burning candles have drawn increased attention in recent years. Soot associated with burning candles can cause property damage including blackening walls, ceilings, and carpets also the smoke can be a major source of particulates in indoor air (IAQ, 2001; EPA Report, 2001 [1]; Wallace, 2000 [2]). Emissions from incense may also contain contaminants that can cause a variety of health effects, In fact, according to the supporting research some candles are known to be quite harmful for our health.

When candles are burned, they emit trace amounts of organic chemicals including acetaldehyde, formaldehyde, acrolein, and naphthalene $[3,4,5,6,1]$. Other by-products released during burning may include carbon monoxide, xylene, acetone, toluene, Polychlorodibenzo-p-dioxins/ Polychlorodibenzofurans [PCDDs/PCDFs] and Polyaromatic Hydrocarbons [PAHs], Friborg et al. [7]; Wallace [2], EPA Report [1], Nance [8], ALAW [9], ASTM Annual Book [10], ASTM [11]. Studies concerning the emissions of specific contaminants from incense smoke specify that benzene, toluene (known carcinogens, as stated by the American Lung Association [9]); and particulate matter may be emitted at concentrations that could pose human health risks (IAQ [1]). Furthermore, a few studies indicate possible genotoxic and mutagenic effects from exposure to the same. ASTM [11] Chang et al. [5] compared mutagenic potencies of incense, formaldehyde, and acetaldehyde to Salmonella typhimurium T102 and concluded that incense smoke contains highly active compounds with a higher mutagenic potency than formaldehyde. Sato et al. [12] and Rasmussen [13] also found that incense smoke is mutagenic to $\mathrm{S}$. typhimurium TA98, TA 100 , and TA104. Incense Smoke Condensates (ISCs), the particles released during incense burning, were found to be mutagenic and/or genotoxic. Chen et al. [14] also found that the genotoxicity of certain ISCs in mammalian cells was higher than particles produced from tobacco smoke condensates (TSCs).

Additionally, a phenomenon known as Black Soot Deposition (BSD) resulted from the burning of candles. Referred to as ghosting, carbon tracking, carbon tracing, and dirty house syndrome, black soot is the product of the incomplete combustion of carbon-containing fuels. Recent research and complaints from the public suggested that the main cause of BSD is none other than frequent candle burning [15]. The amount and type of soot varied from candle to candle, and even though it is composed primarily of elemental carbon, candle soot may include phthalates, lead, and volatiles such as benzene and toluene (Krause, 1999, qtd. EPA Report, 2001). These soot particles when inhaled can potentially penetrate the deepest areas of the lungs, the lower respiratory tract, and the alveoli (Krause, 1999, qtd. EPA Report, 2001). Moreover, carpets, furniture, walls, curtains, and other materials in the home are often stained from soot deposition [16,17]. The soot particles may also be attracted to electrically charged surfaces such as freezers, plastic blinds, television sets, and computers, causing 
blackening as well [15]. BSD has actually become so prevalent within the last few years that people have begun filing insurance claims in order to restore their homes [18].

Burning paraffin wax is consequently responsible for a variety of ills which plague society, both health and non-health related. While the American Lung Association continues to warn consumers of unhealthy indoor air quality from burning these types of candles, the EPA also affirms that indoor air quality is three times more polluted than outdoor air quality.

Many more studies (Preston-Martin et al. [19], Roveri et al. [20], Bridges [21], Sasco et al. [22], LaRosa et al. [23], Yang et al. [24]) have indicated links between exposure to candle/incense smoke and health effects including cancer, asthma, and contact dermatitis, Friborg et al. [25]; EPA 2000 [26]. Clearly, as the following studies and evidences show frequent candle or incense burning is a key factor contributing to the development of these illnesses, especially in the cases of young children. These burnings have been reported in many studies as a major risk factor for developing lung cancer [22,23], asthma [21], and dermatitis $[21,27,28]$. Further studies denote that incense burning has also been a contributing factor in the occurrence of asthma for Quatar children [29], and coughing was found to be associated with incense exposure in a study of Taiwanese children [24]. As in the case of candles, burning incense also produces volatile fragrances that can reach exposed skin causing dermatitis [20]. Similarly, an elevated risk for leukemia was found in children whose parents burned incense during pregnancy or while nursing [30], while a study of childhood brain tumors showed elevated risks for children whose parents burned incense in the home [17].

\section{METHODOLOGY}

All samples used for this study were unscented paraffin candles obtained from various candle companies. Carbon disulfide was purchased from the Fisher Scientific with a quoted purity of $100 \%$ and was used without further purifications. The burning chamber (8" x 8" x 26") attached to a pump on the top, was constructed locally, and
Coconut Charcoal CSC Cat. No. 226-01GWS was purchased from SKC, Inc.

The GC software allowed us to set up four-ramp programs with relatively fast ramping at $5^{\circ}-10^{\circ} \mathrm{C}$ per minute enabling us to find the optimum temperature programming condition for separation. The instrument for testing the emission products were two GC-MS: PERKINELMER Autosystem XL Gas Chromatography, equipped with a $15 \mathrm{~m}$ polyethylene narrow bore column $(0.25 \mathrm{~mm})$ with a temperature range of $-60^{\circ} \mathrm{C}$ to $400{ }^{\circ}$, and Turbomass Gold Mass-spectrometer. The second one was a Shimadzu GC-2010 gas chromatograph and QP-2010s quadruple mass spectrometer, advanced data station, and GC-MS solution software. The QP-2010 system has a mass range of 1.5 - 900 AMU.

A candle burning chamber was constructed so that we were able to pump gaseous emission products through an ampoule containing coconut charcoal capable of adsorbing all organic substances produced from burning the candle. The ampoules were attached to the chamber allowing the emission products to be pumped with a controlled rate permitting the candle to burn as in the normal conditions for five to six hours. The experiments were carried out by burning the candles where the mixture of gases passed through the ampoule at $0.20 \mathrm{~L} / \mathrm{min}$. The contents of the ampoule were transferred into small volume of spectroscopic grade carbon disulfide to extract adsorbed materials. The resulting solution was separated from coconut-charcoal by decanting and poured into a $5-\mathrm{mL}$ volumetric flask and raised to the volume.

The extracted samples were injected to GC-MS system to be separated enabling us to identify possible components. Before injecting these samples, the pure solvent was injected and tested to determine that the solvent was pure and indentified materials were not from possible impurities of the solvent. Chromatograms shown in Figs. 1 through 11 provide information concerning the identity of various substance represented by each peak. These peaks were analyzed by the help of NIST library to identify corresponding emitted substances which is using the fractionation patterns from these samples and comparing with patterns of those in the library for known compounds. 


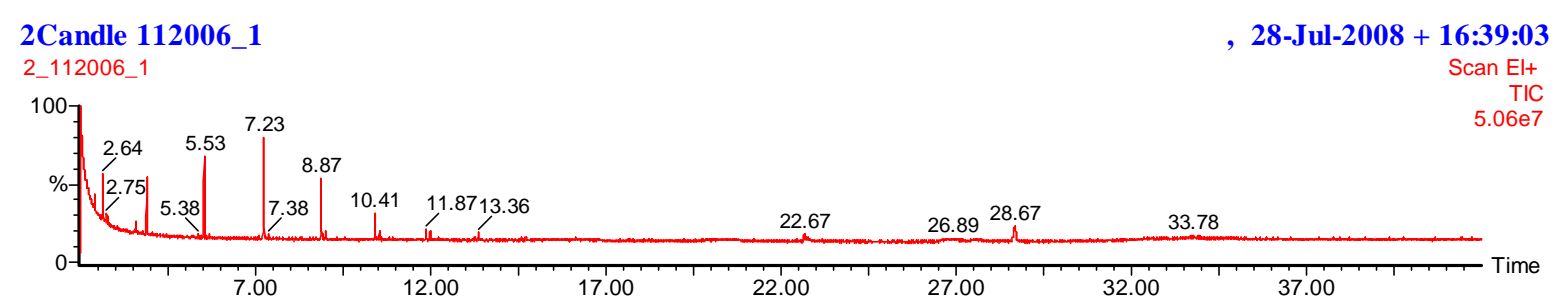

Fig. 1. Chromatogram for a paraffin based candle (112006-1). This figure shows chromatogram of emissions chemicals from candle 112006-1 indicating that there are considerable numbers of pollutants in the emission of this candle. Major pollutants include 1-Heptene (2.64 min); Toluene (3.58 $\mathrm{min})$; 1-Octene (3.90 min); 1-Nonene (5.53 min); 1-Decene (7.23 min); 1-Undecene (8.87 min); 3-Dodecene (10.41 min); 1-Heptanol, 6-methyl(11.87 $\mathrm{min})$

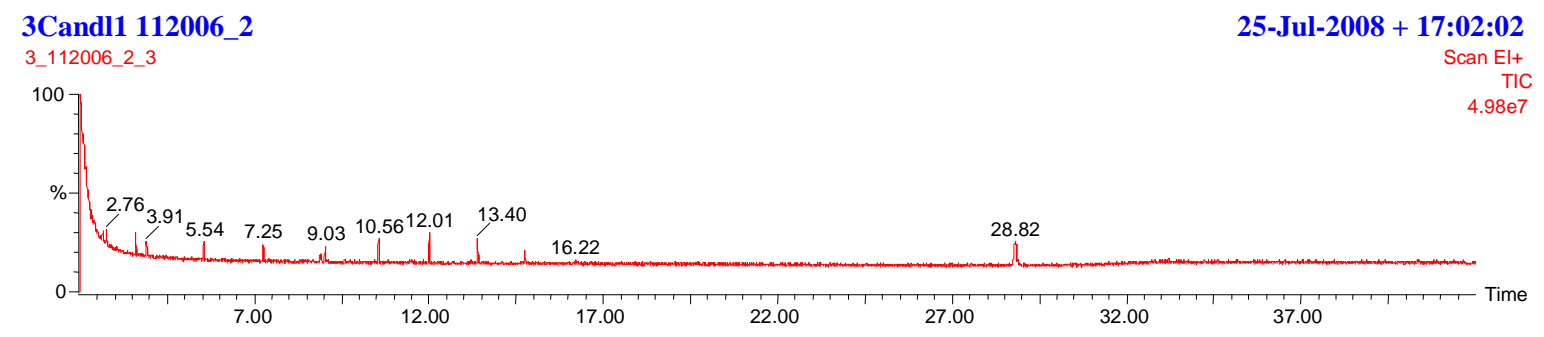

Fig. 2. Chromatogram for un-scented paraffin candle (112006-2). This figure shows the chromatogram of emission materials for candle 112006-2 indicates that the emission products contain various pollutants including 1-heptene (2.65 min); trichloroethylene (2.76 min), toluene (3.59 min); 1-octene (3.91 $\mathrm{min})$, 1-nonene (5.54 min); 1-Octene, 3,7-dimethyl- (7.25 $\mathrm{min})$; tridecane (12.01 $\mathrm{min})$ 


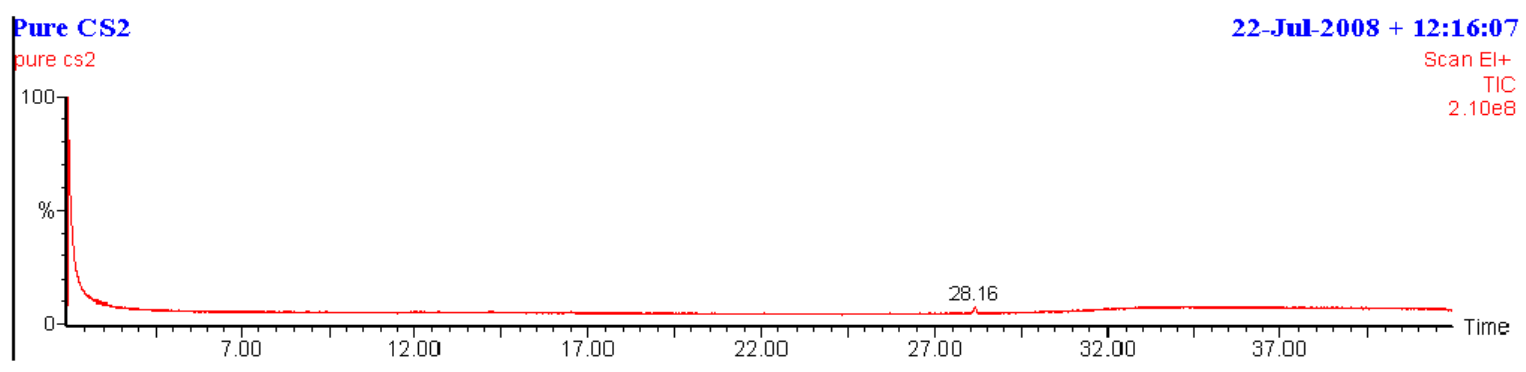

Fig. 3. Chromatogram of pure carbon disulfide, indicating that the solvent was pure (the peak at 28.16 is due to sulfur) and various pollutants are not introduced from any experimental procedures

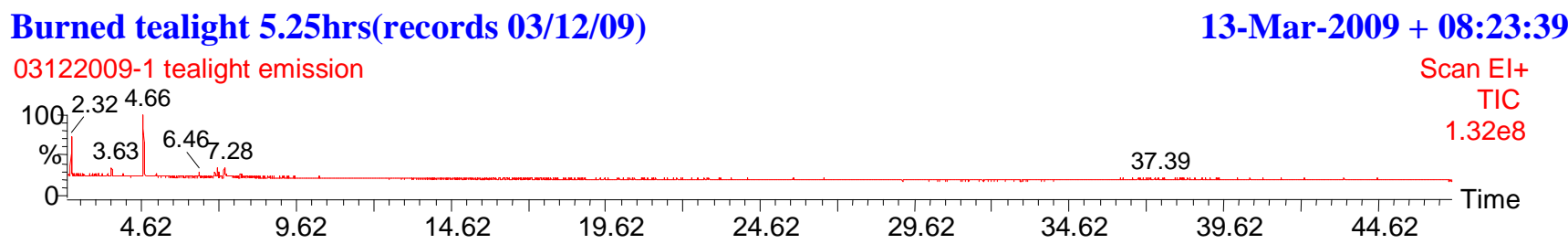

Fig. 4. Chromatogram of a petroleum based-candle, one-tealight, (a paraffin based candle) indicating that it produces some pollutants including Octamethyl-cyclotetrasiloxane (2.32 min); Dimethylthiane (3.63 min), S,S-dioxide; Cyclopentasiloxane, decamethyl- (4.66 min) and Silane, trichlorodocosyl-Cyclohexasiloxane, dodecamethyl- (7.28 $\mathrm{min})$

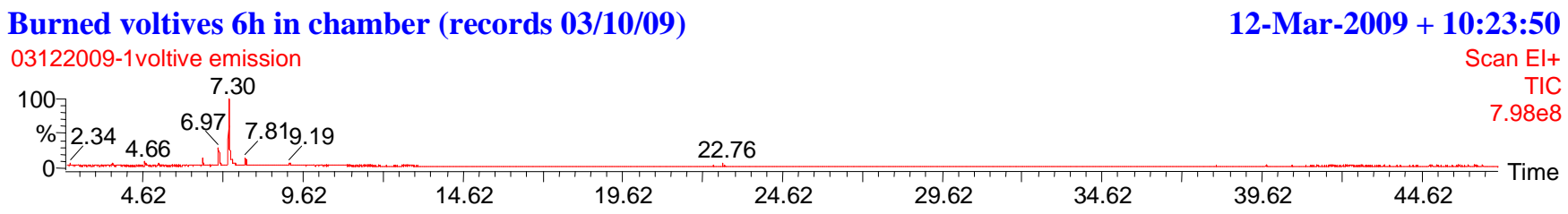

Fig. 5. Chromatogram of emission products of a paraffin candle 1-votive, contains various pollutants including Octamethyl-Cyclotetrasiloxane (2.34 min); 2-Trifluoroacetoxytridecane; 1,5-dimethyl-2-ethenyl-cyclohexane-1-carboxylate and Trichlorodocosyl- silane (9.09 min) 
Burned voltives $6 \mathrm{~h}$ in chamber (records 03/10/09)

03122009-2voltive emission

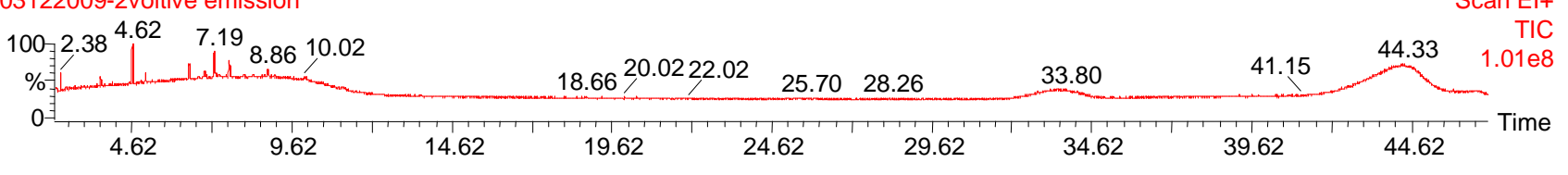

Fig. 6. Chromatogram of the emission products of a paraffin candle (2-votive), It contains variety of hazardous materials including DecamethylCyclopentasiloxane (4.62 min); Propanoic acid, 2-methyl-, 2,2-dimethyl-1-(2-hydroxy-1-methylethyl)propyl ester (6.88 min)

Burned voltives $6 \mathrm{~h}$ in chamber (records 03/10/09)

03122009-3voltive emission

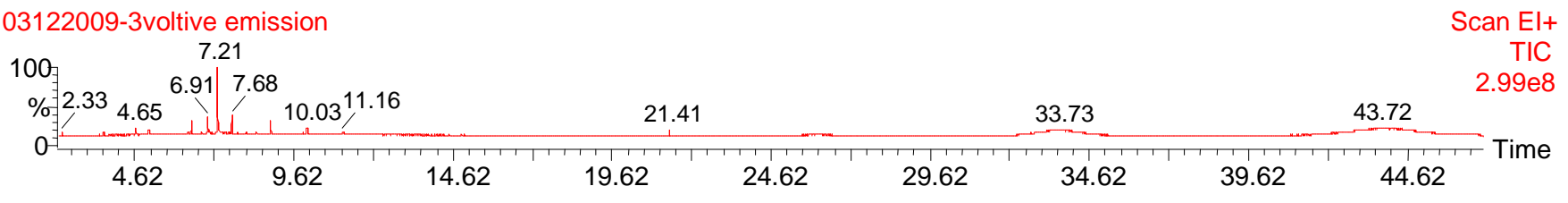

Fig. 7. Chromatogram of the emissions of a paraffin candle (3-votive). The polluting materials for this candle include Octamethylcyclotetrasiloxane, Trichlorodocosyl-silane (2.33 min); Cyclopentasiloxane, decamethyl- (4.65 min); 3-Hexanone, 2,5-dimethyl-4-nitro- (6.72 min); Decamethyl cyclopentasiloxane; 2,5-dimethyl-4-nitro-3-Hexanone; Propanoic acid, 2-methyl-, 2,2-dimethyl-1-(2-hydroxy-1-methylethyl)propyl ester, Propanoic acid, 2-methyl-, 3-hydroxy-2,4,4-trimethylpentyl ester (6.91 min); and Propanoic acid, 2-methyl-, 3-hydroxy-2,4,4-trimethylpentyl ester

Burned voltives 6 h in chamber (records 03/10/09)

03122009-3voltive emission

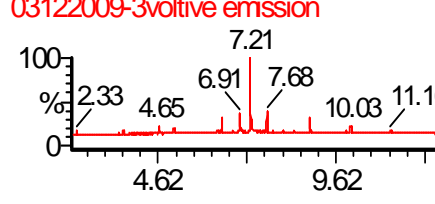

$$
\text { (7.21 min) }
$$

, 12-Mar-2009+ 13:32:35

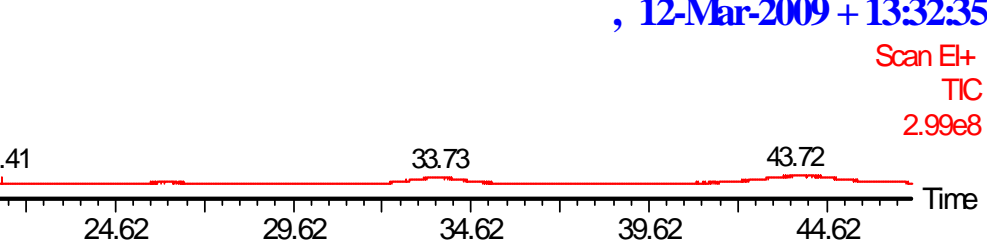

Fig. 8. Chromatogram of the emissions products of a paraffin candle (4-votive). The polluting materials include: Cyclotetrasiloxane, octamethyl(2.33 min); Cyclopentasiloxane, decamethyl- (4.65 min); Propanoic acid, 2-methyl-, 2,2-dimethyl-1-(2-hydroxy-1-methylethyl)propyl ester (6.91 min); Propanoic acid, 2-methyl-, 3-hydroxy-2,4,4-trimethylpentyl ester (7.21 min) 


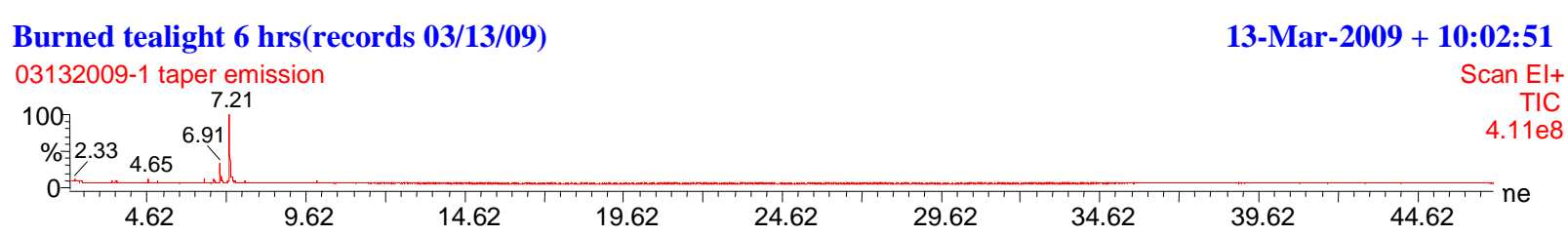

Fig. 9. Chromatogram of emission products of paraffin candle (1-taper). The polluting substances for this candle include Silane, trichlorodocosyl(3.5 min); Propanoic acid, 2-methyl-, 2,2-dimethyl-1-(2-hydroxy-1-methylethyl)propyl ester (6.42 min); 2,2,4-Trimethyl-1,3-pentanediol diisobutyrate (6.91 min).

\section{9-1PE}

03242009-1 pillar emission $1003.50_{5.06} 6.47 .71$

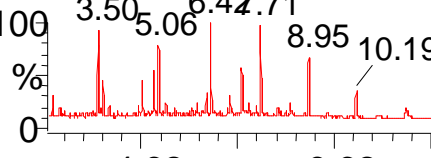
19

Scan $\mathrm{El}+$

TIC

$2.19 \mathrm{e} 8$

Fig. 10. Chromatogram of the emission products of a paraffin candle (1-pillar). As it is apparent from the figure and corresponding mass spectra,

this candle produces good number of pollutants while burning. Some of the pollutants are 1-Methyldecahydronaphthalene (3.57 min);

Naphthalene, decahydro-2-methyl- (3.78 min); Propanoic acid, 2-methyl-, 2,2-dimethyl-1-(2-hydroxy-1-methylethyl)propyl ester (6.92 min); 4-Trifluoroacetoxytetradecane (7.60 min); Perhydrophenanthrene, Perhydrophenanthrene, (4a.alpha., 4b.beta., 8a.beta., 10a.alpha.)Perhydrophenanthrene, (4a.alpha., 4b.beta., 8a.beta., 10a.alpha.)- (8.37 min) 
Hydro32010: 12-April-2010

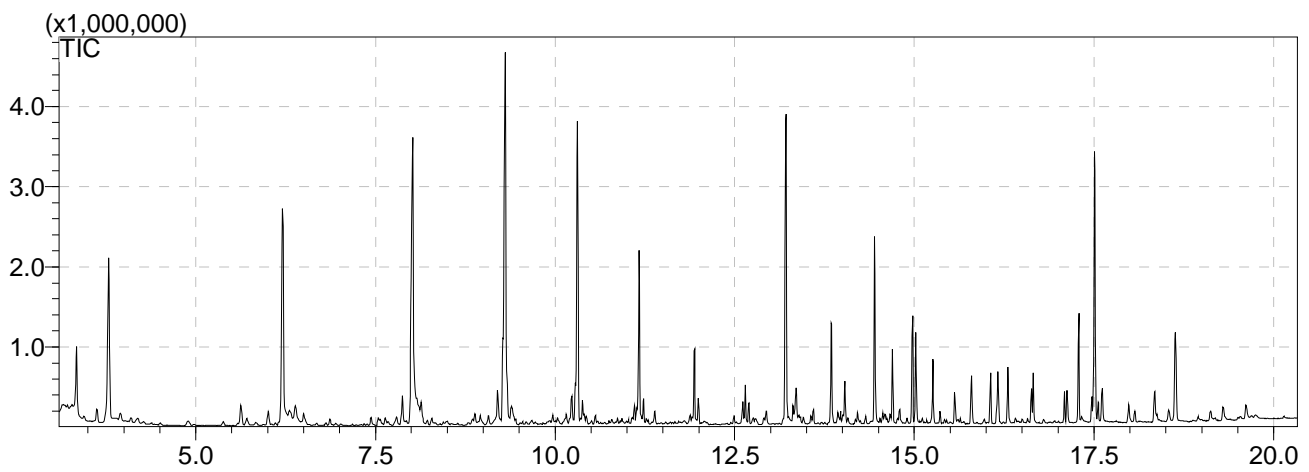

Fig. 11. Chromatogram of the emission products of a paraffin candle (hydro32010)

Table 1. Analysis of candle (hydro32010)

\begin{tabular}{llllllll}
\hline R time & Area & \%Area & Height & \%Height & Area/Height & Name & \%Similarity \\
\hline $\mathbf{3 . 3 3 9}$ & $\mathbf{9 8 5 5 4 7}$ & $\mathbf{1 . 3 9}$ & $\mathbf{7 9 0 2 2 1}$ & $\mathbf{1 . 6 1}$ & $\mathbf{1 . 2 5}$ & Benzene & $\mathbf{9 3}$ \\
5.628 & 384700 & 0.54 & 230956 & 0.47 & 1.67 & Toluene & 95 \\
6.208 & 4974186 & 7.00 & 2663056 & 5.44 & 1.87 & Octene & 98 \\
10.231 & 320118 & 0.45 & 288188 & 0.59 & 1.11 & 1-Undecene & 97 \\
11.168 & 2412671 & 3.39 & 2128492 & 4.35 & 1.13 & 1-Dodecene & 97 \\
13.210 & 4744918 & 6.67 & 3811747 & 7.78 & 1.24 & 1Dodecanol & 98 \\
13.843 & 1457941 & 2.05 & 1243588 & 2.54 & 1.17 & n-Tridecanol-1-ol & 96 \\
14.448 & 2550341 & 3.59 & 2304412 & 4.70 & 1.11 & 1-Hexadecanol & 96 \\
14.972 & 1501376 & 2.11 & 1335482 & 2.73 & 1.12 & Dodecanamide & 98 \\
15.020 & 1175083 & 1.65 & 1123342 & 2.29 & 1.05 & $\begin{array}{l}\text { 1-Hexadecanol } \\
\text { 3-Dimethylaminopropyl }\end{array}$ \\
17.286 & 1476326 & 2.08 & 1346414 & 2.75 & 1.10 & $\begin{array}{l}\text { 9 } \\
\text { methacrylamide }\end{array}$ \\
\hline
\end{tabular}

\section{RESULTS AND DISCUSSION}

The emissions from petroleum based candles that were tested by GC/MS system described above indicated that they contain a variety of polluting materials which are harmful for human health. Extended exposure of human kinds with these unwanted chemical are responsible for a variety of illnesses that could have been avoided by not using them more frequently. The chromatograms for candles clearly indicate that emission products contained large number of pollutants. The analysis of the main peaks for identification purposes are presented above. Some of identified the pollutants representing large peaks included: benzene, 1-heptane, 2,4hexadiyne, toluene, 1-octene, 1-nonene, 1decene, undecene, dodecene, 1-heptanol, 6methyl, some of which like benzene and toluene are serious hazard for human health.

Table 1 is the results of major peak analysis for candle hydro32010.

\section{CONCLUSION}

Among the varieties pollutants detected in the emissions of candles are benzene and toluene.

Exposure to benzene has been linked to the development of blood cancers and blood disorders. Most serious is benzene's ability to cause leukemia, a fatal cancer of the white cells that produces tissue. Benzene primarily attacks the blood-forming tissues and damages the bone marrow where red blood cells, white blood cells, and platelets are formed.

The principle effect of toluene exposure is central nervous system depression. Toluene may affect the liver, kidneys, and nervous system; the nervous system appears to be most sensitive to its effects and its causes of irritation to the skin, eyes and respiratory tract.

Most data concerning toluene's effects on human health comes from studies of workers with 
chronic exposure to toluene and from intentional solvent abusers who inhale high levels of toluene for self-intoxication. The applicability of this data to relatively low-level exposure in the environmental setting, however, is unknown.

Octamethyl-cyclotetrasiloxane is considered harmful to the environment. Acute effects of 1octene cause skin, eye, respiratory irritation, drowsiness, and chemical pneumonia. Symptoms include a burning sensation, coughing, wheezing, shortness of breath, headache, nausea, and vomiting. Ingestion results in low oral toxicity as long as aspiration, (breathing liquid into the lungs) is avoided. Symptoms of aspiration include severe irritation, pneumonitis, and pulmonary edema. Also, CNS depression, dizziness, confusion, and loss of consciousness may occur; skin contact may cause drying or deflating of the skin.

Inhalation of high concentrations of decahydronaphthalene may cause central nervous system, effects characterized by nausea, headache, dizziness, unconsciousness and coma. Respiratory tract irritation and kidney damage are additional problems.

It is the present authors' interest and aims to inform the public that burning candles, specifically paraffin based candles, are hazardous to human health. Candles are burned all over the world, and this is done mainly indoors that people inhale the emission product even long after the burning has finished. This certainly would cause maximum damage to individuals within that household because of individual's breathing the same polluted indoor air for a longer period of time.

Burning candles also damages walls, furnishings, and other properties that economically would not be favorable. Healthy people are productive and more industrious than unhealthy ones, hence, staying healthy would be more advantageous economically.

From the result of this investigation, one could easily conclude that burning candles just for fun might be interesting however its use should be reduced to special occasions to minimize complications.

\section{CONSENT}

It is not applicable.

\section{ETHICAL APPROVAL}

It is not applicable.

\section{COMPETING INTERESTS}

Authors have declared that no competing interests exist.

\section{REFERENCES}

1. EPA Report 2001. "Candles and Incense as Potential Sources of Indoor Air Pollution: Market Analysis and Literature Review, "dated Jan. 2001. Prepared by National Risk Management, Research Laboratory.

2. Wallace L. Real-time monitoring of particles, $\mathrm{PAH}$, and $\mathrm{CO}$ in an occupied townhouse. Applied Occupational Environmental Hygiene. 2000;15(1):39-47.

3. Lau C, et al. Levels of selected organic compounds in materials for candle production and human exposure to candle emissions. Chemosphere. 1997;34(5-7): 1623-1630.

4. Cheng YS, Bechtold WE. Incense smoke: Characterization and dynamics in indoor environments. Aerosol Science and Technology. 1995;23:271-281.

5. Chang HL, Kuo ML, Lin JM. Mutagenic activity of incense smoke in comparison to formaldehyde and acetaldehyde in Salmonella typhimurium TA102. Bulletin of Environmental Contamination and Toxicology. 1997;58:394-401.

6. The American Society for Testing and Materials, International. 2002. ASTM Annual Book of Standards, Standard F. 2179-02.

7. Friborg JT, Yuan JM, Wang R, Koh WP, Lee $\mathrm{HP}, \mathrm{Yu} \mathrm{MC}$. Incense Use and Respiratory Tract Carcinomas: A Prospective Cohort Study. Cancer. 2008;113:7,1676-84.

8. Nance P, Strawson J, Zhao J. Review of candle emissions literature and recommendations. Toxicology for Excellence Risk Assessment (TERA). Electronic version; 2005.

Available:www.aboutaircare.com/documen ts/tera.doc (on June 27, 2007.

9. ALAW (American Lung Association in Washington). Candles. Accessed Oct 25, 2009.

10. The American Society for Testing and Materials, International. ASTM Annual 
Book of Standards, Standard F. 2004;2417-04.

11. The American Society for Testing and Materials, International. ASTM Annual Book of Standards, Standard F. 2000;2058-00.

12. Sato S, Makino R, Takahashi $Y$, Sugimura $\mathrm{T}$, Miyazaki T. Mutagenicity of smoke condensates from joss sticks. Mutat Res. 1980;77:31-36.

13. Rasmussen RE. Mutagenic activity of incense smoke in Salmonella-typhimurium. Bulletin of Environmental Contamination and Toxicology. 1987;38:827-833.

14. Chen $\mathrm{BH}$, et al. Indoor air pollution in developing countries. World Health Statistics Quarterly. 1990;43:127.

15. Krause D, 1999-2006. Black Soot Deposition. Bailey Engineering Corporation. Electronic version. Available:http://www.baileyeng.com/black soot deposition.htm

16. Vigil F. Black stains in houses: Soot, dust, or ghosts? Home Energy. 1998;15(1):15.

17. LaPrade JC. The use of candles is associated with the black soot deposition phenomenon. Environmental Education Series Timely Information Newsletter. Auburn University; 1999. AL. June 11.

18. Images of insure, black soot on walls, 2009

19. Preston-Martin S, Yu MC, Benton B, Henderson BE. N-Nitroso compounds and childhood brain tumors: A case-control study. Cancer Res. 1982;42:5240-5245.

20. Roveri P, Andrisano V, Di Pietra AM, Cavrini V. GC-MS analysis of incenses for possible presence of allergenic nitromusks. J Pharm Biomed Anal. 1998;17:393-398.

21. Bridges $B$. Fragrance: emerging health and environmental concerns. Flavor Fragrance Journal. 2002;17:361-371.

22. Sasco AJ, Merrill RM, Dari I, BenhaimLuzon V, Carriot F, Cann Cl, Bartal M. A case-control study of lung cancer in Casablanca, Morocco. Cancer Causes and Control. 2002;13:609-616.

23. LaRosa LE, Buckley TJ, Wallace LA. Realtime indoor and outdoor measurements of black carbon in an occupied house: an examination of sources, J. Air Waste Manage. Assoc. 2002;52:41-49.

24. Yang CY, Chiu JF, Cheng MF, Lin MC. Effects of indoor environmental factors on respiratory health of children in a subtropical climate. Environmental Research. 1997;75(1):49-55.

25. Friborg JT, Yuan JM, Wang R, Koh WP, Lee HP, Yu MC. Incense use and respiratory tract carcinomas: A prospective cohort study. Cancer. 2008;113(7):167684.

26. EPA. Integrated Risk Information System (IRIS). Substance file- benzene. Washington, D.C. National Center for Environmental Assessment; 2000a.

Available:http://www.epa.gov/ngispgm3/iris /subst/0276.htm (accessed August 31, 2000).

27. Bonnekoh B, Merk HF. Airborne allergic contact dermatitis from benzoyl peroxide as a bleaching agent of candle wax. Contact Dermatitis. 1991;24:367-368.

28. Api AM, Bredbenner A, McGowen M, Niemiera D. Skin contact transfer of three fragrance residues from candles to human hands. Regulatory Toxicology and Pharmacology. 2007;48:279-283.

29. Dawod ST, Hussain AA. Childhood asthma in Qatar. Annals of Allergy, Asthma, \& Immunology. 1995;75(4):360-4.

30. Lowengart RA, Peters JM, Cicioni C, Buckley J, Bernstein L, Preston-Martin S, Rappaport E. Childhood leukemia and parents' occupational and home exposures. J Natl Cancer Inst. 1987;79:3946.

(c) 2017 Massoudi and Hamidi; This is an Open Access article distributed under the terms of the Creative Commons Attribution License (http://creativecommons.org/licenses/by/4.0), which permits unrestricted use, distribution, and reproduction in any medium, provided the original work is properly cited.

Peer-review history:

The peer review history for this paper can be accessed here: http://sciencedomain.org/review-history/20001 